\title{
Correction to: Glutamine Antagonist JHU083 Normalizes Aberrant Glutamate Production and Cognitive Deficits in the EcoHIV Murine Model of HIV-Associated Neurocognitive Disorders
}

\author{
Michael T. Nedelcovych ${ }^{1,2,3} \cdot$ Boe-Hyun $\mathrm{Kim}^{4} \cdot$ Xiaolei Zhu $^{3,5} \cdot$ Lyndah E. Lovell $^{1,2,3}$ - Arena A. Manning ${ }^{3,6}$. \\ Jennifer Kelschenbach ${ }^{3,4}$. Eran Hadas ${ }^{4}$. Wei Chao ${ }^{4}$. Eva Prchalová ${ }^{1,2,3} \cdot$ Ranjeet P. Dash ${ }^{1,2,3} \cdot$ Ying Wu $^{1,2,3}$.

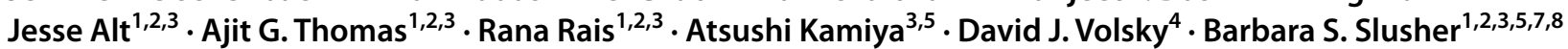

Published online: 29 April 2021

(c) Springer Science+Business Media, LLC, part of Springer Nature 2021

\section{Correction to: J Neuroimmune Pharmacol (2019) 14:391-400 https://doi.org/10.1007/s11481-019-09859-w}

The original version of this article unfortunately contained a mistake. For David Volsky's 2nd award, it is listed as R01MH105145 but the correct grant number should be R01MH104145.

The original article has been corrected.
The original article can be found online at https://doi.org/10.1007/ s11481-019-09859-w.

David J. Volsky

david.volsky@mssm.edu

Barbara S. Slusher

bslusher@jhmi.edu

1 Johns Hopkins Drug Discovery, 855 North Wolfe Street, Baltimore, MD 21205, USA

2 Department of Neurology, Johns Hopkins University School of Medicine, Baltimore, MD, USA

3 Department of Oncology, Johns Hopkins University School of Medicine, Baltimore, MD, USA

4 Department of Medicine, Icahn School of Medicine at Mount Sinai, Annenberg Building Floor 21, Room 42, 1468 Madison Ave, New York, NY 10029, USA
Publisher's Note Springer Nature remains neutral with regard to jurisdictional claims in published maps and institutional affiliations.
5 Department of Psychiatry and Behavioral Sciences, Johns Hopkins University School of Medicine, Baltimore, MD, USA

6 Graduate Program in Neuroscience, University of Washington, Seattle, WA, USA

7 Department of Neuroscience, Johns Hopkins University School of Medicine, Baltimore, MD, USA

8 Department of Medicine, Johns Hopkins University School of Medicine, Baltimore, MD, USA 